\title{
Adalimumab Immunogenicity Is Negatively Correlated with Anti-Hinge Antibody Levels in Patients with Rheumatoid Arthritis ${ }^{\Phi}$
}

\author{
Keito Hoshitsuki, ${ }^{1}$ Sanjay Rathod, ${ }^{1}$ Manda J. Ramsey, Lei Zhu, Larry W. Moreland, \\ and Christian A. Fernandez \\ Center for Pharmacogenetics and Department of Pharmaceutical Sciences (K.H., S.R., M.J.R., C.A.F.) and Rheumatology and \\ Clinical Immunology (L.Z., L.W.M.), University of Pittsburgh, Pittsburgh, Pennsylvania
}

Received June 22, 2020; accepted September 16, 2020

\begin{abstract}
Patients with rheumatoid arthritis $(\mathrm{RA})$ are frequently treated with anti-tumor necrosis factor- $\alpha$ immunoglobulin therapy but develop neutralizing antibodies against these drugs, necessitating therapeutic monitoring of drug concentrations and anti-drug antibodies. Patients with RA have multiple factors related to their autoimmune disposition that interfere with conventionally used methods to detect anti-drug antibodies. Currently deployed analytical methods have significant limitations that hinder clinical interpretation and/or routine use, and no method can detect immunogenicity and drug levels simultaneously to provide clinically meaningful recommendations. Given these limitations, the objective of this study was to identify sources of and associations with assay interference in patients with RA. We designed a modular immunogenicity and drug concentration detection technology to identify the factors that interfere with the detection of adalimumab and anti-adalimumab antibodies in a cohort of 206 patients with RA. Patients were included from the University of Pittsburgh Rheumatoid Arthritis Comparative Effectiveness Research registry. In this cohort, we analyzed clinical and plasma factors associated with anti-adalimumab and anti-hinge antibodies. A novel flow cytometry-based assay was developed and validated that simultaneously measures adalimumab and anti-adalimumab antibody concentrations,
\end{abstract}

overcoming many of the interference factors that are limitations of conventional assays, including anti-fragment crystallizable (Fc) and anti-hinge antibodies. C-reactive protein $(P=0.035)$, Disease Activity Score-28 (DAS28) score $(P=0.002)$, and disease activity category $(P=0.009)$ were significantly associated with anti-adalimumab antibodies but not with anti-hinge antibodies $(P>0.05)$. Anti-hinge antibodies were inversely associated with drug-neutralizing antibodies $(P=0.002)$. In patients with RA, anti-hinge antibodies may have a potential protective effect against the development of anti-adalimumab antibodies.

\section{SIGNIFICANCE STATEMENT}

Using a novel cytometric assay that simultaneously measures drug and anti-drug antibodies, we overcame many interferences that hinder the clinical interpretation of adalimumab immunogenicity testing. Our investigation in patients with RA demonstrated that immunogenicity impaired the pharmacological action of adalimumab via analysis of RA disease severity markers. We also demonstrate that patients with anti-hinge antibodies had lower anti-adalimumab antibody levels and decreased drug neutralization. Our results suggest that anti-hinge antibodies can predict adalimumab immunogenicity before the start of therapy.
This study was supported by University of Pittsburgh School of Pharmacy and National Institute of Health National Cancer Institute [C.A.F.; R01CA216815]. The Rheumatoid Arthritis Comparative and Effectiveness Research (RACER) study was funded initially by National Institute of Arthritis and Musculoskeletal and Skin Diseases [L.W.M.; RC2-AR-0589] and then by Genentech. K.H. was supported by the Rho Chi Society and American Foundation for Pharmaceutical Education. L.W.M. was funded by the Margaret Jane Miller Endowed Professor for Arthritis Research Chair.

The authors declare no conflicts of interest.

${ }^{1}$ K.H. and S.R. contributed equally to this work.

https://doi.org/10.1124/jpet.120.000179.

S This article has supplemental material available at jpet.aspetjournals.org.

\section{Introduction}

Anti-tumor necrosis factor- $\alpha$ (TNF $\alpha)$ therapy is essential for the treatment of several immunologic and rheumatologic disease states, including rheumatoid arthritis (RA) (NavarroSarabia et al., 2005; Aletaha and Smolen, 2018; Mian et al., 2019). Anti-TNF $\alpha$ immunoglobulin therapy, such as adalimumab and infliximab, are recommended after therapeutic failure of first-line conventional disease-modifying antirheumatic drugs (typically methotrexate) (Singh et al., 2016; Smolen et al., 2017; Aletaha and Smolen, 2018; Mian et al., 2019). These drugs are highly effective in reducing disease activity or severity (Weinblatt et al., 2003; Keystone et al., 2004; Navarro-Sarabia et al., 2005); however, a major

ABBREVIATIONS: ABT, antigen-binding test; APC, Allophycocyanin; bELISA, bridge ELISA; BSA, bovine serum albumin; CRP, C-reactive protein; Fab, antigen-binding fragment; Fc, fragment crystallizable; MFI, mean fluorescence intensity; NHP, normal human plasma; nMFI, normalized mean fluorescence intensity; RA, rheumatoid arthritis; RACER, Rheumatoid Arthritis Comparative and Effectiveness Research; RF, rheumatoid factor; RT, room temperature; TNF $\alpha$, tumor necrosis factor- $\alpha$. 
limitation to their use is their immunogenicity (Bendtzen, 2015a). The development of neutralizing antibodies strongly predicts compromised therapeutic efficacy due to reduction in the achieved drug exposure (Radstake et al., 2009; Bartelds et al., 2010, 2011; Chen et al., 2015; Jani et al., 2015; Strand et al., 2020). Given the high predictive value of anti-drug antibodies in predicting drug exposure and therapeutic failure, therapeutic drug monitoring of anti-drug antibody titers and drug concentrations is essential for achieving and maintaining disease remission.

Several methods have been developed to detect antiadalimumab antibodies. However, when deployed in clinical practice for use in the target patient population, they face significant limitations that can impede interpretation and routine use (Bendtzen, 2015b; Ogrič et al., 2017). The most common technique is the ELISA, such as the bridging ELISA (bELISA). The bELISA requires anti-adalimumab antibodies to simultaneously cross-link the plate-bound adalimumab for capture and the labeled drug for detection (Hart et al., 2011). Although easy to perform and inexpensive, the bELISA can yield both false-negative and false-positive results from multiple sources of interference, which can impede interpretation. A major limitation is the inability to measure antiadalimumab antibodies in the presence of therapeutic drug in the sample, both as a result of competition with the labeled drug used for detection (Hart et al., 2011) and formation of immune complexes that block the Fab arms of the antiadalimumab antibody (van Schouwenburg et al., 2013), both of which can lead to false-negative signals. Another source of potential false-negative results is from undetected IgG subtypes that are not bivalent (i.e., IgG4), which are not negligible with prolonged immunization (van Schouwenburg et al., 2012). False-positive signals can result from rheumatoid factors that bridge the Fc regions of the adsorbed and labeled adalimumab, interfering with the desired interaction with the variable domains of anti-adalimumab antibodies (Bendtzen, 2015b). A common alternative is the antigen-binding test (ABT), another bridging assay typically using radiolabeled bivalent intact $\mathrm{Fab}$ arms $\mathrm{F}\left(\mathrm{ab}^{\prime}\right)_{2}$ from adalimumab to detect anti-adalimumab antibody captured on a Sepharose-bound substrate (e.g., protein A) (Rispens et al., 2012, 2013). One improvement over the bELISA is that the ABT should be free of rheumatoid factor interference given the use of adalimumab fragments lacking the $\mathrm{Fc}$ region in place of the intact antibody for detection. However, this assay is still prone to interference, such as from therapeutic adalimumab immune complexes, therapeutic antibody capture on the Sepharose-bound substrate, and other autoantibodies (Hart et al., 2011). Other methods, such as the acid-dissociation radioimmunoassay and $\mathrm{pH}$-shift anti-idiotype assays, have improvements to overcome drug-anti-drug immune complexes but still require the use of radiation, presenting hazards that preclude routine clinical use (Bendtzen, 2015b; Ogrič et al., 2017). Currently, there is no validated method to detect both adalimumab drug concentrations and anti-adalimumab antibodies simultaneously.

Given the various factors that may interfere with the detection of adalimumab and anti-adalimumab antibodies, the objective of this study was to identify potential sources and associations with assay interference in patients with RA. We enrolled patients with RA, both naive and treated with adalimumab, and characterized their plasma for sources of interference by designing a modular system that can detect antigen-specific binding as well as interference by autoantibodies to the Fc, hinge, and Fab regions of adalimumab IgG1 antibody. In the process, we developed a high-throughput cytometric-based method resistant to many of the identified interferences to simultaneously detect anti-adalimumab antibodies and adalimumab drug concentrations. Finally, we found associations between patient clinical characteristics and anti-adalimumab antibodies and that anti-hinge antibodies inversely associate with neutralizing anti-adalimumab antibodies.

\section{Materials and Methods}

\section{Patient Cohort}

The studied patients were enrolled from the University of Pittsburgh Rheumatoid Arthritis Comparative Effectiveness Research (RACER) registry. RACER has continuously enrolled patients older than 18 years who have been diagnosed with RA by rheumatologists at the University of Pittsburgh Medical Center. The RACER registry protocol was approved by the University of Pittsburgh Institutional Review Board, and all enrolled patients gave informed consent prior to enrollment.

\section{Adalimumab Digestion and Biotinylation}

Preparation of $\mathbf{F}\left(\mathbf{a b}^{\prime}\right)_{2}$ and Fab. $\mathrm{F}\left(\mathrm{ab}^{\prime}\right)_{2}$ and $\mathrm{Fab}$ monoclonal antibody fragments were prepared from $4 \mathrm{mg}$ of adalimumab (AbbVie Inc.) by pepsin and papain digestion, respectively, using Pierce $\mathrm{F}\left(\mathrm{ab}^{\prime}\right)_{2}$ and Fab Preparation Kit (Thermo Scientific). Enzymatic adalimumab digestion was confirmed by electrophoresis under nonreducing conditions. The final protein concentrations of the generated fragments were determined by BCA kit (Thermo Fisher).

Biotinylation. $\mathrm{F}\left(\mathrm{ab}^{\prime}\right)_{2}, \mathrm{Fab}$, and $\mathrm{TNF} \alpha$ (Miltenyi Biotec, Germany) were biotinylated using Thermo EZ-Link Sulfo-NHS-LC Biotinylation Kit (Thermo Scientific). The final concentrations were determined by Nanodrop 2000.

\section{Detection of Anti-Adalimumab Antibodies by $F\left(a b^{\prime}\right)_{2}$-Based Assay}

A total of $1.7 \times 10^{5}$ SPHERO 6 - $\mu \mathrm{m}$ streptavidin-coated polystyrene beads (Spherotech) were added to 96 -well microtiter plates (Corning) and washed ( $0.1 \%$ Tween 20/PBS). In total, $100 \mu \mathrm{l} /$ well of $2 \mu \mathrm{g} / \mathrm{ml}$ biotinylated digested adalimumab $\mathrm{F}\left(\mathrm{ab}^{\prime}\right)_{2}$ fragments in buffer (Tris/ $10 \%$ BSA $/ 0.05 \%$ Tween 20 ) was added to washed beads and incubated for 15 minutes at room temperature (RT) on a shaker. Beads were washed and blocked with $100 \mu \mathrm{l} /$ well of $5 \%$ BSA in PBS for 15 minutes at RT on a shaker. Samples were diluted 1:100 and added to the plate, incubated for 1 hour at RT on a shaker, and washed. For detection, $100 \mu \mathrm{l}$ (1:100 diluted) anti-human IgG Fc-APC (Biolegend) was added and incubated overnight on a shaker at $4^{\circ} \mathrm{C}$, washed, and resuspended in $200 \mu \mathrm{l}$ of running buffer/PBS and acquired by flow cytometry (MACSQuant analyzer 10 flow cytometer; Miltenyi Biotec). Negative controls were beads alone or wash buffer only; positive control was $300 \mathrm{ng} / \mathrm{ml}$ of human anti-adalimumab IgG1 (HCA204; Biorad) prepared in $1 \%$ normal human plasma (NHP). Mean fluorescence intensities (MFIs) were recorded. Normalized MFI (nMFI) was calculated by subtracting off the background MFI, transforming logarithmically, and dividing the transformed MFI by the transformed MFI of the negative control. Samples were considered positive for antiadalimumab antibodies if nMFI exceeded three times the S.D. of the adalimumab-naïve training set.

Determination of Rheumatoid Factor Interference. To determine whether rheumatoid factor (autoantibodies directed against the Fc region of IgG) interferes with detection of anti-adalimumab, the extent to which anti-human IgG Fc labeled with APC bound to streptavidin 
beads coated with adalimumab $\mathrm{F}\left(\mathrm{ab}^{\prime}\right)_{2}$-biotin, $\mathrm{TNF} \alpha$-biotin, buffer, or to protein $\mathrm{G}$ beads coated with adalimumab was determined.

Detecting Autoantibody Interference during the Capture of Anti-Adalimumab Using Adalimumab $\mathbf{F}\left(\mathbf{a b}^{\prime}\right)_{2}$ and Estimating Anti-Hinge Antibody Levels. After blocking the beads, $20 \mu \mathrm{g} / \mathrm{ml}$ of human IgG F $\left(\mathrm{ab}^{\prime}\right)_{2}$ recombinant protein (009-0104; Rockland) in PBS was added and incubated for 1 hour at RT on a shaker and subsequently detected as above. Samples with greater than or equal to $50 \%$ decrease in $\mathrm{MFI}$ after the addition of $\mathrm{F}\left(\mathrm{ab}^{\prime}\right)_{2}$ were considered antihinge-positive.

\section{Detection of Anti-Adalimumab Antibodies by Fab-Based Assay}

The procedure was identical to the $\mathrm{F}\left(\mathrm{ab}^{\prime}\right)_{2}$-based assay above except for the substitution of the biotinylated digested adalimumab $\mathrm{F}\left(\mathrm{ab}^{\prime}\right)_{2}$ fragment with the Fab fragment. No IgG $\mathrm{F}\left(\mathrm{ab}^{\prime}\right)_{2}$ competition was performed.

\section{Simultaneous Detection of Adalimumab and Anti-Adalimumab Antibodies by Flow Cytometry}

A total of $1.7 \times 10^{5}$ SPHERO streptavidin-coated polystyrene beads 6 and $2 \mu \mathrm{m}$ in size (Spherotech) were added to 96-well microtiter plates (Corning) and washed (0.1\% Tween 20/PBS). In total, $50 \mu \mathrm{l}$ of $2 \mu \mathrm{g} / \mathrm{ml}$ biotinylated digested adalimumab $\mathrm{F}\left(\mathrm{ab}^{\prime}\right)_{2}$ fragment or $2.5 \mu \mathrm{g} / \mathrm{ml}$ biotinylated TNF $\alpha$ prepared in buffer (Tris/10\% BSA/0.05\% Tween 20 ) was added to 6 - and $2-\mu \mathrm{m}$ beads, respectively. After incubation for 15 minutes at RT on a shaker, beads were washed with buffer and blocked with $100 \mu \mathrm{l} /$ well $5 \%$ BSA in PBS for 15 minutes at RT on a shaker. Different concentrations of adalimumab $(7.5-1000 \mathrm{ng} / \mathrm{ml})$ were prepared and spiked with 10 or $100 \mathrm{ng} / \mathrm{ml}$ of anti-adalimumab antibody in PBS. Samples were added to the prepared beads and incubated for 1 hour at RT on a shaker. Adalimumab and antiadalimumab antibodies were detected using anti-human IgG Fc-APC and flow cytometry as described for Detection of Anti-Adalimumab Antibodies by $F\left(a b^{\prime}\right)_{2}$-Based Assay. Unbound beads alone were used as negative control.

\section{Detection of Anti-Adalimumab Antibodies by Bridge ELISA}

Microtiter plates (Corning) were precoated overnight at $4^{\circ} \mathrm{C}$ with $100 \mu \mathrm{l} /$ well of adalimumab capture antibody at $1 \mu \mathrm{g} / \mathrm{ml}$ (AbbVie Inc.) in PBS. After washing (0.1\% Tween 20 in PBS), plates were blocked with 5\% BSA in PBS for 1 hour at RT. After washing, $50 \mu \mathrm{l} /$ well of samples and controls were added (10\% NHP in PBS as negative and $0.625 \mu \mathrm{g} / \mathrm{ml}$ anti-adalimumab IgG1 as positive controls, respectively) and incubated for 1 hour at RT. After incubation, plates were washed before the addition of $100 \mu \mathrm{l} \mathrm{of} 2 \mu \mathrm{g} / \mathrm{ml}$ of horseradish peroxidaseconjugated adalimumab detection antibody and incubated for 1 hour at RT on a shaker. After washing, $100 \mu \mathrm{l}$ of $o$-phenylenediamine dihydrochloride was added and incubated for 30 minutes with protection from light. The reaction was then stopped by acidification with $100 \mu \mathrm{l}$ of $1 \mathrm{M}$ phosphoric acid, and the absorbance was measured at $490 \mathrm{~nm}$. For standard calibration curves of anti-adalimumab antibodies, human anti-adalimumab antibody standards (HCA204; Biorad) were serially diluted in $10 \%$ NHP/0.1\% Tween 20/PBS in triplicate. Final concentration of anti-adalimumab antibodies covered the range of $0.1-10,000 \mathrm{ng} / \mathrm{ml}$. Plasma anti-adalimumab concentrations were interpolated from the calibration curve.

\section{Ex Vivo Adalimumab Neutralization}

Adalimumab concentration was measured with and without $300 \mathrm{ng}$ of adalimumab spiked into patient plasma samples diluted 1:100 in PBS. Percent neutralization was calculated as 1 - (adalimumab concentration after spike/adalimumab concentration before spike) $\times$ 100. Negative control was $300 \mathrm{ng} / \mathrm{ml}$ of human anti-adalimumab IgG1 (HCA204; Biorad) in 1\% NHP, and positive control was the mixture of
$300 \mathrm{ng} / \mathrm{ml}$ of adalimumab, human anti-adalimumab IgG1, and $20 \mu \mathrm{g} / \mathrm{ml}$ of human IgG $\mathrm{F}\left(\mathrm{ab}^{\prime}\right)_{2}$.

\section{Demonstrating Interference by Anti-Hinge Antibody}

Adalimumab $\mathrm{F}\left(\mathrm{ab}^{\prime}\right)_{2}$ and $\mathrm{Fab}$ fragment bound beads were prepared as described above. Anti-human IgG1 hinge antibody (9052; SouthernBiotech) was added, incubated, washed, and detected with antihuman IgG Fc antibodies labeled with APC.

\section{Statistical Analysis}

Baseline characteristics were evaluated by unpaired two-sample $t$ test or Wilcoxon rank-sum for continuous variables, depending on whether the data were normally distributed or not. Wilcoxon ranksum was used for ordinal variables, and Fisher's exact test was used for nominal variables. Differences between groups were analyzed with Wilcoxon rank-sum for continuous and ordinal variables for two groups, Kruskal-Wallis with Dunn post-test for multiple comparisons for more than two groups, Fisher's exact test for categorical variables, and Pearson correlation coefficient $\left(r^{2}\right)$ to compare anti-adalimumab signals measured by Fab versus $\mathrm{F}\left(\mathrm{ab}^{\prime}\right)_{2}$-based assay. The univariable analyses were conducted using the generalized linear model for assessing the association between clinical outcomes and antiadalimumab and anti-hinge signals for the covariates $\mathrm{RF}$ factor status, DAS28 score, disease activity category, $\log _{10}$ C-reactive protein (CRP), and anti-adalimumab antibody status. The effect size was calculated as the natural exponentiation of the $\beta$-coefficient. $\mathrm{R}$ statistical software (version 2.13.2) and GraphPad Prism 8.4 (GraphPad Software, CA) were used. The criterion of significance was $\alpha=$ 0.05 . All values in text and figures are means \pm S.D. unless specified otherwise.

\section{Results}

A total of 206 patients from the RACER study enrolled between February 15, 2010, and May 9, 2011, were included in this substudy and evaluated. Patients in the adalimumabtreated cohort must have received adalimumab for $\geq 6$ months $(n=91)$, and patients in the adalimumab-naïve cohort had no documented previous exposure to adalimumab $(n=115)$. Clinical characteristics at the time of sample collection are provided in Table 1. Patients were majority female sex. Of the 206 patient samples available for this study, information regarding the use of methotrexate was available for only $44 \%$ of patients, and a majority of those were receiving concomitant methotrexate therapy. Overall, patients were generally well controlled on therapy, with a median DAS28 score of 2.8. Patients naïve for adalimumab were older and had lower DAS28 scores.

Given the need to develop a high-throughput, clinically meaningful adalimumab immunogenicity testing platform and to design a modular system to assess interference factors, a novel flow cytometry-based detection method was developed to overcome many of the limitations of previous methods. Capture of anti-adalimumab antibodies and adalimumab was achieved using biotinylated adalimumab $\mathrm{F}\left(\mathrm{ab}^{\prime}\right)_{2}$ and $\mathrm{TNF} \alpha$, respectively, conjugated to streptavidin-coated beads of two different sizes, allowing for discrimination between and adalimumab and anti-adalimumab antibodies by flow cytometry gated on side/forward scatter (Fig. 1; Supplemental Fig. 1). Different assay parameters were optimized during method development, including the concentration of adalimumab $\mathrm{F}\left(\mathrm{ab}^{\prime}\right)_{2}$, the number of streptavidin beads, and the detection antibody incubation time (Supplemental Fig. 2). Our cytometric 
TABLE 1

Characteristics of patients enrolled in study $(n=206)$

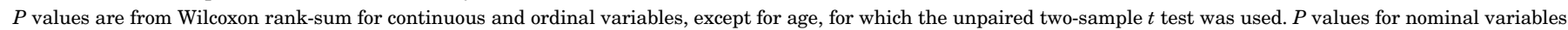
are from Fisher's exact test.

\begin{tabular}{|c|c|c|c|}
\hline & Adalimumab Treated $(n=91)$ & Adalimumab Naïve $(n=115)$ & $P$ Value \\
\hline Female, $n(\%)$ & $67(73.6)$ & $86(74.8)$ & 0.874 \\
\hline Age, yr, mean \pm S.D. & $55.8 \pm 12.0$ & $64.6 \pm 14.2$ & $<0.001$ \\
\hline Disease duration, yr, median (IQR) & $11.7(5.1-18.0)$ & $10.5(4.9-20.4)^{a}$ & 0.654 \\
\hline DAS28 score, median (IQR) & $3.0(2.1-4.0)$ & $2.7(1.8-3.5)^{b}$ & 0.025 \\
\hline Disease activity category, $n(\%)$ & & $b$ & 0.026 \\
\hline Remission & $34(37.4)$ & $51(45.1)$ & \\
\hline Low & $14(15.4)$ & $29(25.7)$ & \\
\hline Moderate & $34(37.4)$ & $30(26.5)$ & \\
\hline Severe & $9(9.9)$ & $3(2.7)$ & \\
\hline CRP (mg/dl), median (IQR) & $3.0(1.1-8.4)$ & $4.3(1.8-9.7)^{a}$ & 0.093 \\
\hline Rheumatoid factor positive, $n / n$ available for analysis (\%) & $52 / 78(66.7)$ & $29 / 49(59.2)$ & 0.450 \\
\hline Self-reported or physician-reported methotrexate use, $n / n$ available for analysis $(\%)$ & $51 / 63(80.9)$ & $73 / 91(80.2)$ & 0.999 \\
\hline
\end{tabular}

IQR, interquartile range.

${ }^{a} n=114$ available for analysis.

${ }^{b} n=113$ available for analysis.

methods demonstrated negligible binding by rheumatoid factors to antibody fragments or beads but strong binding to adalimumab, as expected (Supplemental Fig. 3). The linear ranges of anti-adalimumab and adalimumab antibody detection were between 1-150 and 79-600 ng/ml, respectively (Fig. 2, $\mathrm{A}$ and $\mathrm{B})$. To demonstrate the ability to detect anti-adalimumab antibodies in the presence of therapeutic adalimumab from the same sample simultaneously, we created an artificial system of adalimumab and anti-adalimumab antibodies spiked into NHP at several concentrations and detected them by flow cytometry (Fig. 2, C and D). Our data indicate that the effect of antiadalimumab antibodies on the free adalimumab available for attenuating $\mathrm{TNF} \alpha$ is dependent on both the concentrations of adalimumab and anti-adalimumab. We found that low levels of anti-adalimumab can have less than a $25 \%$ decrease in free adalimumab concentrations, whereas increasing adalimumab concentrations in the presence of antibodies can rescue drug neutralization. Our results suggest that dose escalations can increase adalimumab levels in patients with low levels of antidrug antibodies to assure efficacy.

When RACER patient cohort samples were initially assayed using this cytometric method and adalimumab $\mathrm{F}\left(\mathrm{ab}^{\prime}\right)_{2}$ for capture, anti-adalimumab signals were detected unexpectedly in patients that were adalimumab-naïve (Fig. 3A), indicating that potential interference is not solely due to anti-Fc autoantibodies. Upon clinical verification of true naïve status and based on previous studies (Rispens et al., 2012), we hypothesized that patients with RA had autoantibodies directed against $\mathrm{F}\left(\mathrm{ab}^{\prime}\right)_{2}$, likely the hinge region of the antibody. The assay was initially modified to outcompete the interfering antibodies with human $\operatorname{IgG} \mathrm{F}\left(\mathrm{ab}^{\prime}\right)_{2}$. This reduced the false detection (Fig. 3, A and B), suggesting that the false-positive results were due to autoantibodies against a component of $\mathrm{F}\left(\mathrm{ab}^{\prime}\right)_{2}$ or rather anti-hinge antibodies. Based on the change in MFI after the addition of $\operatorname{IgG~} \mathrm{F}\left(\mathrm{ab}^{\prime}\right)_{2}$, we found that $51 \%$ of patients with RA were positive for anti-hinge antibodies, and there was no significant difference in the proportion of patients with anti-hinge antibodies between the adalimumab-naïve versus treated cohorts (Fig. 3C, $54 \%$ vs. $46 \%, P=0.262$ ).

Using samples from 86 patients who were adalimumabnaive as a training set (75\% of naïve cohort), an antibody positive threshold was established at $2.1458 \mathrm{nMFI}$. This threshold was able to identify $100 \%$ of adalimumab-naïve test set samples $(n=29)$ as negative for anti-adalimumab antibodies (Fig. 4A). We then tested samples from patients receiving adalimumab and found that $4.4 \%$ of RACER patients receiving adalimumab met our predefined threshold of anti-adalimumab IgG antibody positivity, consistent with many of these patients receiving concomitant methotrexate (Krieckaert et al., 2012). Given the utility of our cytometric methods, we confirmed that patients with the highest antiadalimumab antibody nMFI signals were truly positive for anti-adalimumab neutralizing antibody by confirming greater adalimumab neutralization ex vivo relative to adalimumabnaïve patients and normal human plasma (Fig. 4B, $P<$ 0.0001). Furthermore, the patient antibody status results from the cytometry method were compared with the standard bELISA. The bELISA failed to discriminate anti-adalimumab antibodies in adalimumab-naïve versus treated patients (Supplemental Fig. 4). In this patient population, the bELISA only had a specificity of $35 \%$ for patients naïve for adalimumab and $23 \%$ for patients treated with adalimumab (Supplemental Table 1).

We next verified that the interfering antibodies directed against $\mathrm{F}\left(\mathrm{ab}^{\prime}\right)_{2}$ were anti-hinge autoantibodies. We modified the detection method by preparing adalimumab Fab fragments lacking the hinge region for anti-adalimumab capture in place of $\mathrm{F}\left(\mathrm{ab}^{\prime}\right)_{2}$. As expected, anti-hinge antibodies did not bind to Fab adalimumab fragments, whereas they bound to $\mathrm{F}\left(\mathrm{ab}^{\prime}\right)_{2}$ adalimumab (Supplemental Fig. 5). Consistent with these data, we measured anti-adalimumab levels using Fab capture in all RACER patients included in this study and found a strong correlation between both capture methods (Fig. $4 \mathrm{C}, r=0.75, P<0.0001$ ). This supports our hypothesis that much of the false-positive assay interference was due to anti-hinge autoantibodies.

Using the clinical anti-adalimumab data collected in the RACER cohort, we performed exploratory analyses to identify clinical characteristics of patients with RA and markers of disease progression associated with anti-adalimumab antibodies and anti-hinge antibodies (Fig. 5; Supplemental Table 2). Our results indicate that patients with higher antiadalimumab antibody levels were enriched for rheumatoid factor (Fig. 5A, $P=0.057$ ) and had positive correlations with CRP (Fig. 5B, $P=0.012$ ) and DAS28 scores (Fig. $5 \mathrm{C}, P=0.002$ ). 
A
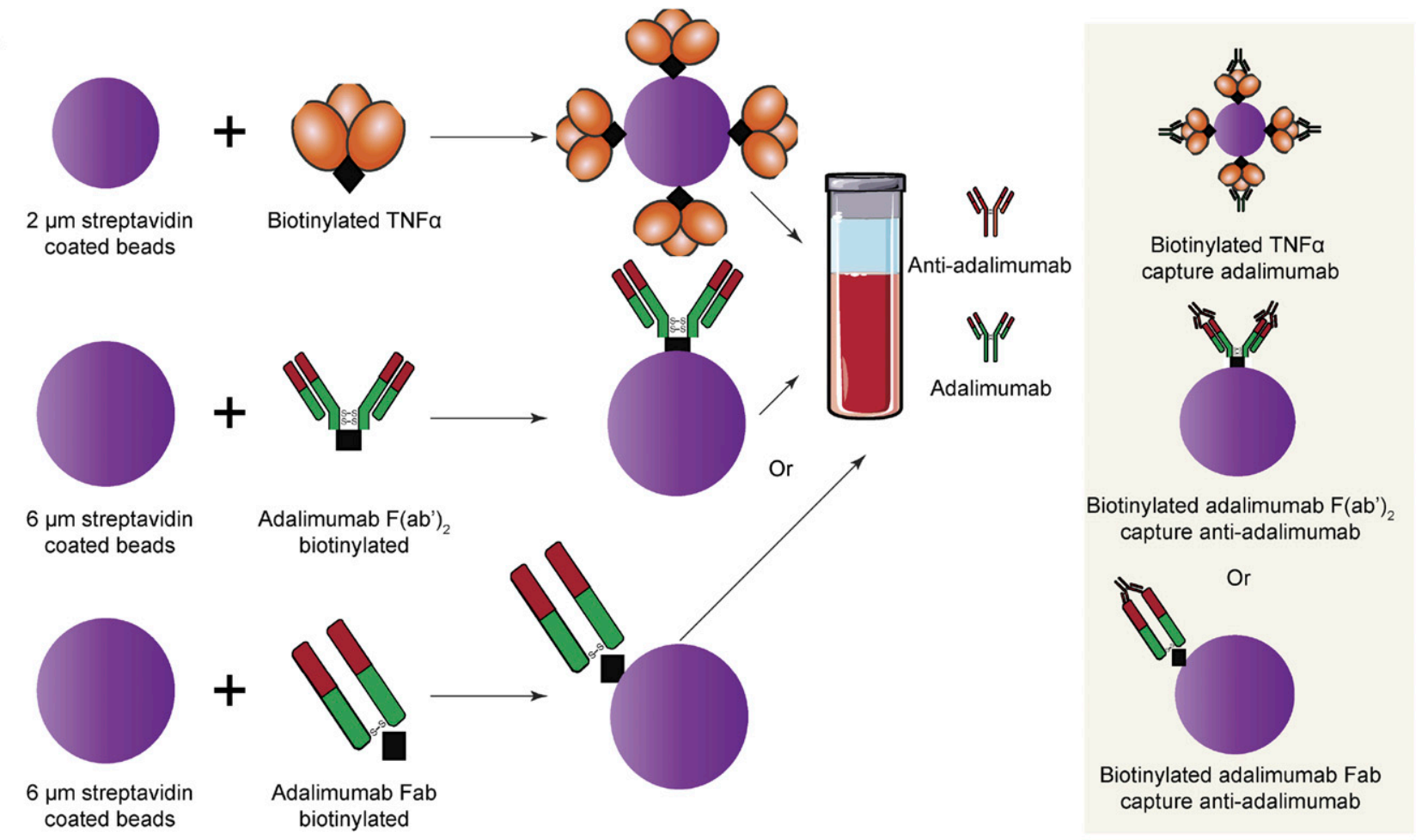

B
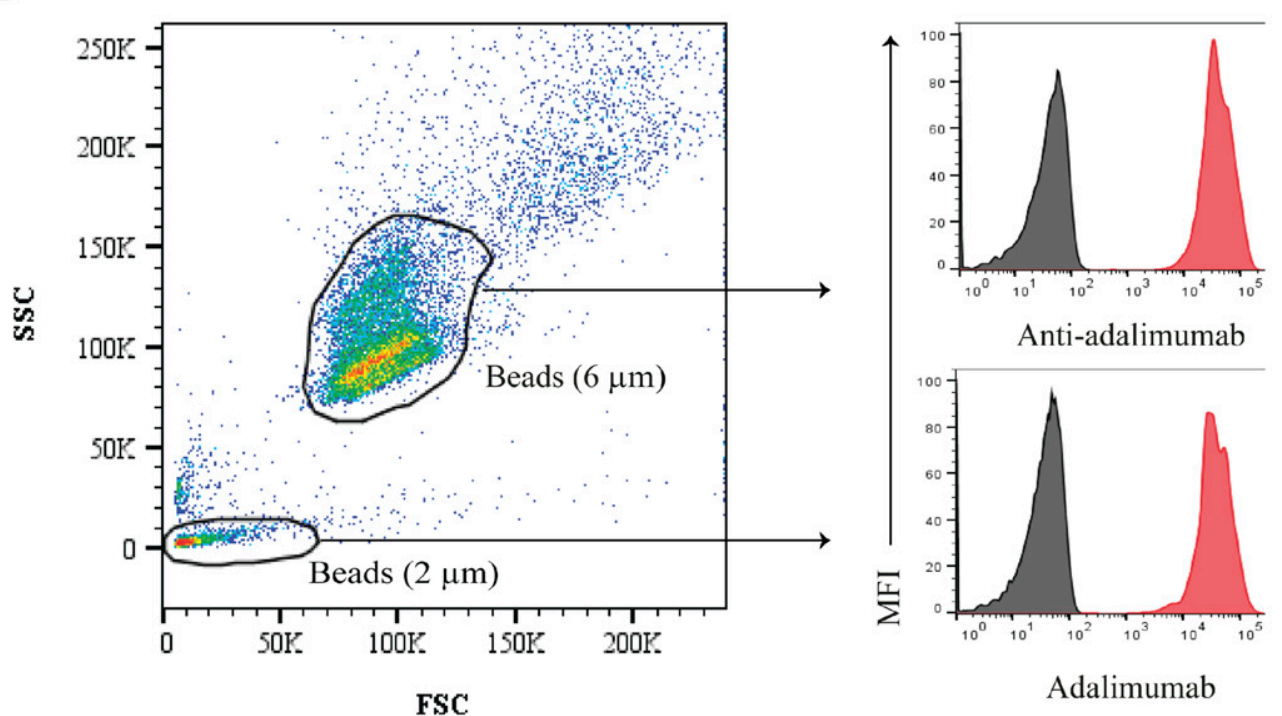

Fig. 1. Flow cytometry gating strategy identifies adalimumab and anti-adalimumab antibodies simultaneously. (A) Adalimumab was captured with TNF $\alpha$ bound to $2-\mu \mathrm{m}$ streptavidin-coated polystyrene beads, and anti-adalimumab antibodies were captured with adalimumab $\mathrm{F}\left(\mathrm{ab} \mathrm{b}^{\prime}\right)_{2}$ or $\mathrm{Fab}$ bound to 6 - $\mu \mathrm{m}$ streptavidin beads. (B) Adalimumab and anti-adalimumab antibodies were detected by flow cytometry gated on side/forward scatter. FSC, forward scatter; SSC, side scatter.

Consistent with greater disease severity being associated with greater anti-adalimumab antibodies, patients with moderate to severe disease activity had higher anti-adalimumab antibody levels than patients in remission or with low disease activity (Fig. 5D, $P=0.009$ ). Unexpectedly, among a subset of samples with anti-hinge antibody and neutralization data, we found that patients with more anti-hinge antibodies had less adalimumab neutralization (Fig. $6 \mathrm{~A}, P=0.002$ ), in contrast to our previous finding of a positive correlation between anti-adalimumab levels and adalimumab neutralization
(Fig. 4B). Based on the association between anti-hinge antibody levels and anti-adalimumab neutralization, we next assessed whether there were additional associations between antihinge antibody levels and other markers of immune responses. Consistent with the association between anti-hinge antibodies and anti-adalimumab neutralization, we found a negative correlation between anti-hinge and anti-adalimumab antibody levels (Fig. $6 \mathrm{~B}, P=0.028$ ) and with anti-adalimumab antibody positivity (Fig. $6 \mathrm{C}, P=0.026$ ). However, there was no association between anti-hinge antibody levels and rheumatoid 


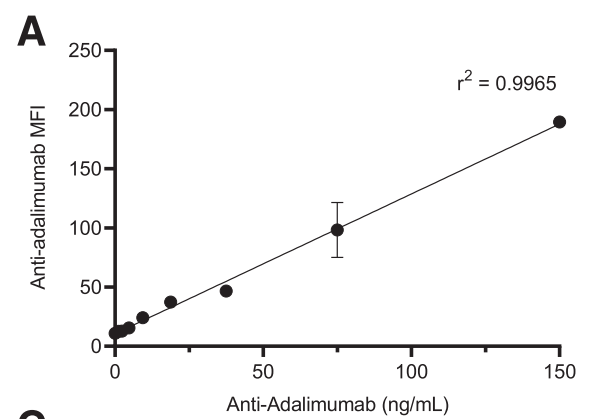

C
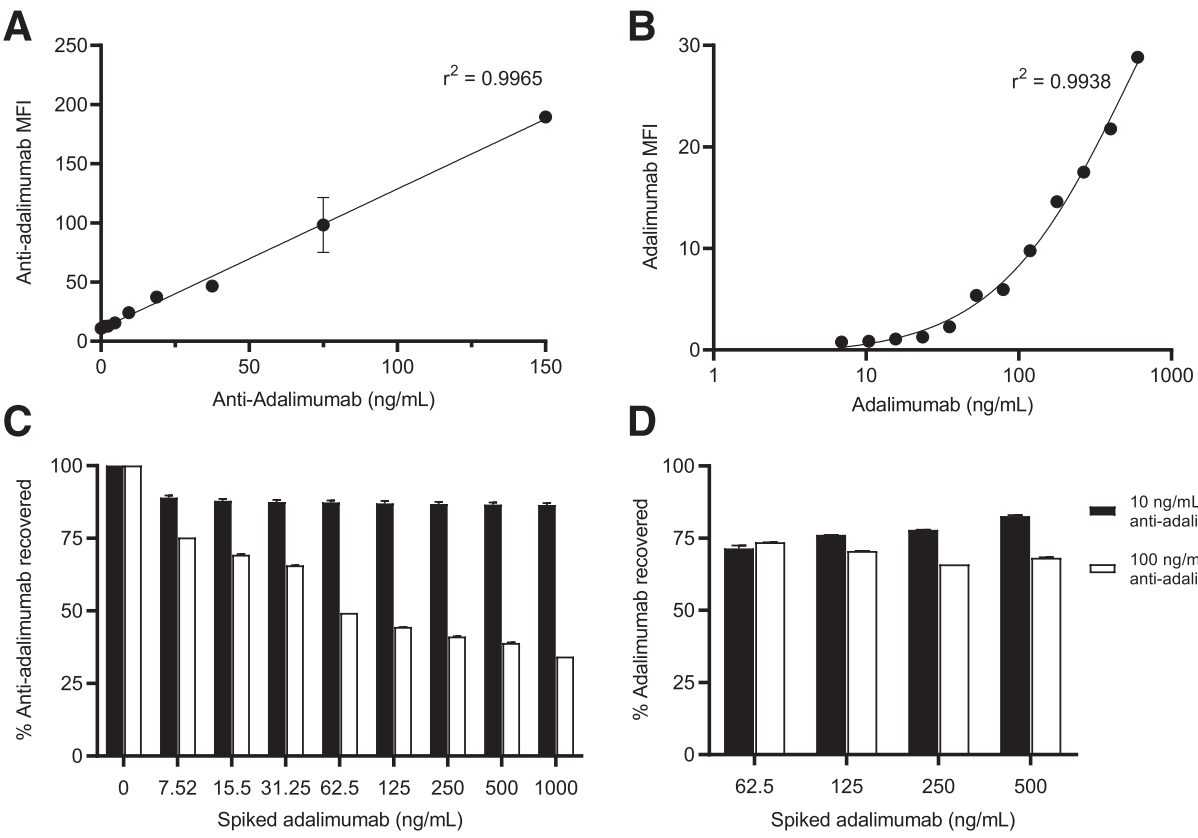

D

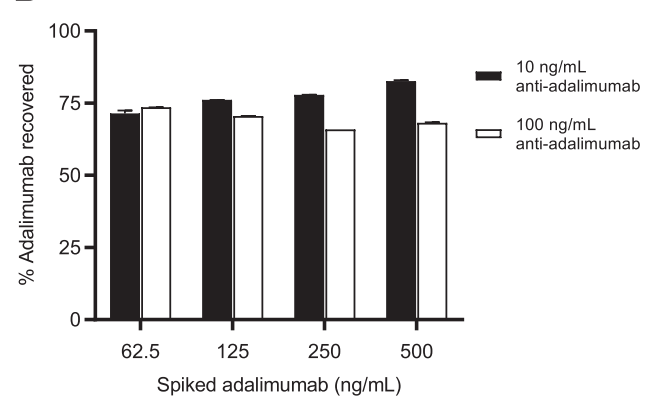

Fig. 2. The cytometric assay measures anti-adalimumab and adalimumab simultaneously over several orders of magnitude. (A) Using anti-adalimumab mAb, anti-adalimumab linearity was established between 1 and $150 \mathrm{ng} / \mathrm{ml}$, with a lower limit of detection of $0.5 \mathrm{ng} / \mathrm{ml}$. (B) Using known spiked concentrations of adalimumab, the linear range of adalimumab detection was established between 79 and $600 \mathrm{ng} / \mathrm{ml}$, with a lower limit of detection of $3.2 \mathrm{ng} / \mathrm{ml}$. (C and D) Antiadalimumab IgG1 (10 and $100 \mathrm{ng} / \mathrm{ml}$ ) was spiked into serially diluted adalimumab, and anti-adalimumab and adalimumab antibody concentrations were measured simultaneously by flow cytometry. (C) Percent anti-adalimumab recovery is represented as the anti-adalimumab MFI detected at that adalimumab concentration relative to MFI detected without adalimumab spike. (D) Percent adalimumab recovery is represented as the adalimumab MFI detected relative to MFI detected without anti-adalimumab IgG1 at the serially diluted concentration. $\mathrm{mAb}$, monoclonal antibody. factor, disease activity, or CRP levels (Supplemental Fig. 6, A-D, $P>0.05$ ). Altogether, our data indicate that our novel cytometric adalimumab immunogenicity method can detect clinically meaningful antibodies and that anti-hinge antibodies may be able to identify patients more likely to develop immunogenicity to adalimumab.

\section{Discussion}

In this clinical study of patients with RA, we demonstrate the presence of several factors that interfere with the detection of anti-adalimumab antibodies. We describe a novel flow cytometry-based assay that overcomes many of these interferences and simultaneously measures adalimumab drug concentrations and anti-adalimumab antibodies in patient plasma samples. Consistent with previous studies, we found that patients with RA and no prior adalimumab exposure inherently have factors that can cause false-positive antiadalimumab signals or rather that bind to the adalimumab molecule and are recognized by the secondary antibody used for detection. Our approach using papain to enzymatically digest adalimumab and capture anti-adalimumab antibodies with Fab fragments confirmed that patients with RA have anti$\mathrm{F}\left(\mathrm{ab}^{\prime}\right)_{2}$ autoantibodies directed primarily against the hinge region of the molecule. Our analysis in both naïve and adalimumab-treated patients demonstrates that these autoantibodies are present before adalimumab exposure. Furthermore, we found that markers of worse RA disease severity (higher DAS28 score and CRP) and autoimmunity (RF positivity) were associated with higher anti-adalimumab antibody levels. Furthermore, we recapitulated the limitations of the conventional bELISA, which can cause false positives in 70\%-90\% of patients with RA with rheumatoid factor (Dörner et al., 2004; Tatarewicz et al., 2010), by demonstrating poor specificity for detecting anti-adalimumab antibodies in both patients with and without prior adalimumab exposure.

Even though the ABTs are slightly more robust alternatives to the bELISA, the anti-hinge antibodies present in patients with RA will also lead to false-positive signals if radiolabeled $\mathrm{F}\left(\mathrm{ab}^{\prime}\right)_{2}$ fragments are used and bound on the Sepharose-bound substrate for anti-adalimumab capture (Rispens et al., 2012). We demonstrate in our cytometric assay that this falsepositive anti-adalimumab signal can be reduced by outcompeting the nonspecific binding with human $\operatorname{IgG~} \mathrm{F}\left(\mathrm{ab}^{\prime}\right)_{2}$. Furthermore, the lower limits of detection for the bELISA and ABT have been reported as approximately 20 and $120 \mathrm{ng} /$ ml, respectively (Hart et al., 2011). The method developed here is more specific and sensitive, allowing quantification of anti-adalimumab antibody concentrations between 1 and $150 \mathrm{ng} / \mathrm{ml}$, with a lower limit of detection of $0.5 \mathrm{ng} / \mathrm{ml}$ in plasma samples from patients with RA, while also providing simultaneous quantification of adalimumab concentrations from the same sample (Fig. 2). Our modular system can also be readily modified to measure the immunogenicity and drug concentrations of other anti-TNF $\alpha$ therapeutics. The benefit or our system versus other methods is that analysis of drug concentrations along with anti-drug antibodies facilitates clinical decision making. Nevertheless, further studies are needed to determine the antibody-to-drug levels requiring treatment interventions for the clinical implementation of this system. Because of the lack of a "gold standard" assay comparison for validation, correlation with clinical response and adalimumab concentrations in patient cohorts would be needed (Williams et al., 2012).

Consistent with previous studies that found associations with anti-adalimumab antibodies and DAS28 scores (Bartelds et al., 2010; Chen et al., 2015; Jani et al., 2015), we identified that more severe RA disease was associated with higher antiadalimumab antibody levels. As we demonstrated ex vivo, these antibodies neutralize adalimumab activity, which likely decrease active drug exposure and compromise therapeutic efficacy in vivo. However, it is also possible that more severe RA immunopathology and autoimmunity could contribute to anti-adalimumab antibody formation, as we observed that RFpositive patient samples had higher anti-adalimumab MFIs than those that were RF-negative. It is also possible that the 


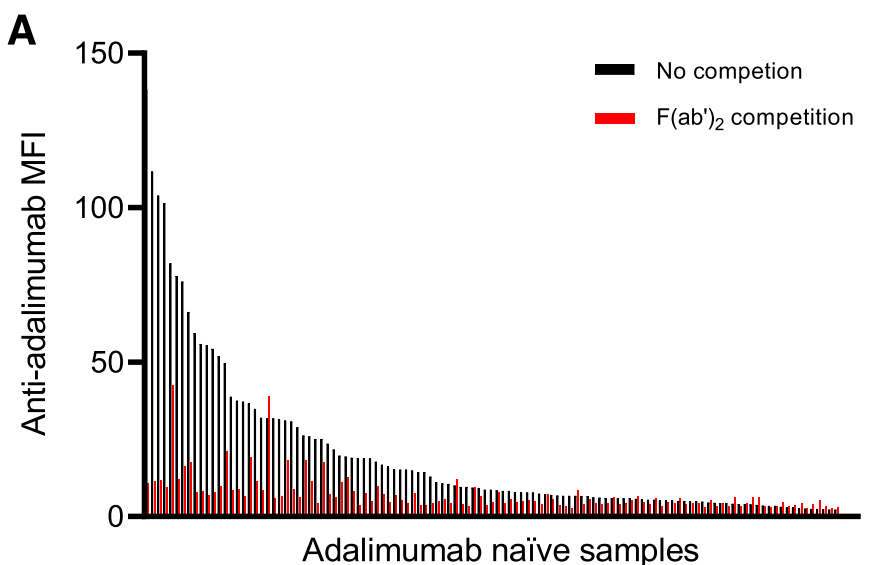

B

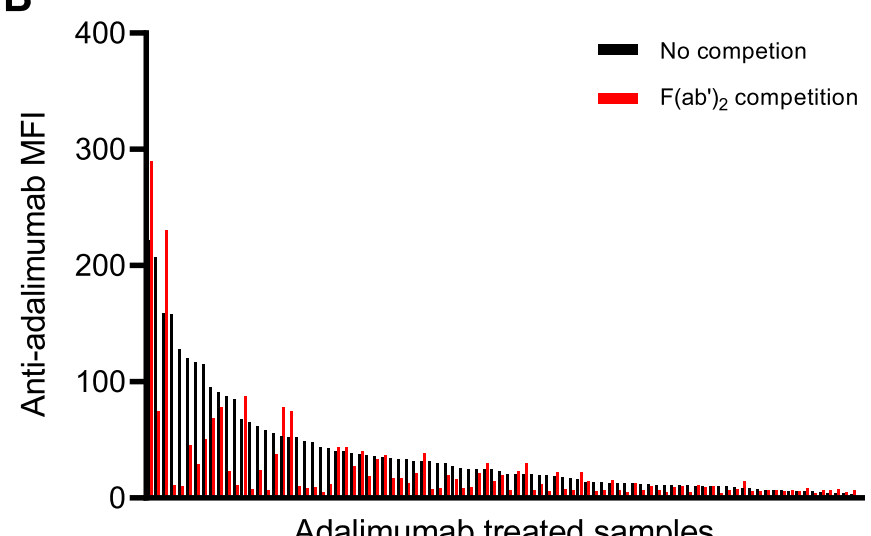

C

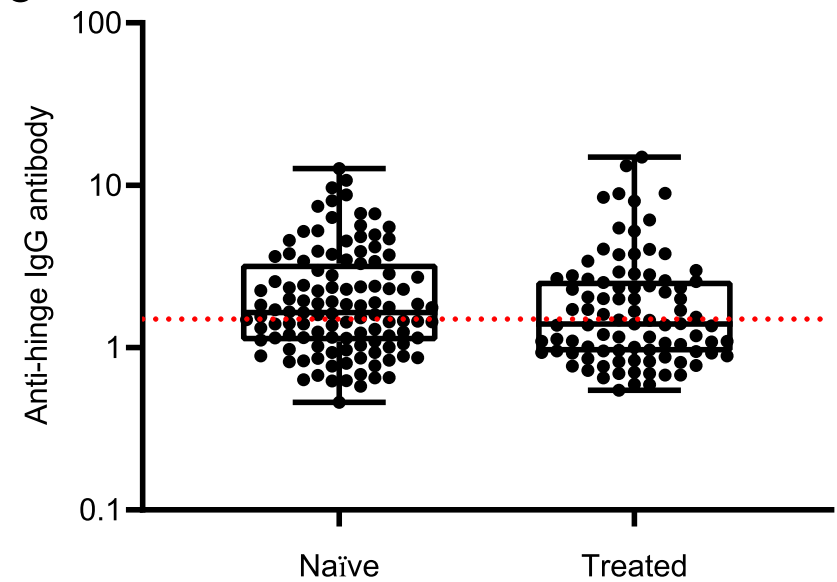

Fig. 3. Anti-hinge antibodies interfere with the detection of anti-drug antibodies. A total of 115 samples from patients with no previous adalimumab exposure (A) and 91 samples from patients treated with adalimumab (B) were evaluated by flow cytometry and resulted in high anti-adalimumab MFIs. The addition of $20 \mu \mathrm{g} / \mathrm{ml}$ of human IgG F $\left(\mathrm{ab}^{\prime}\right)_{2}$ reduced the anti-adalimumab MFI signals in both naïve and adalimumabtreated patients. (C) There was no difference between adalimumab-naïve vs. treated groups in MFI fold-change or proportion of patients positive for anti-hinge antibodies. Anti-hinge-positive status was defined as $\geq 1.5$-fold change as shown by the horizontal line.

recognition of adalimumab's Fc region (i.e., in RF-positive patients) facilitates the development of a true anti-adalimumab response in patients with $\mathrm{RA}$.

Consistent with other studies, we demonstrated the presence of anti-hinge antibodies in patients with RA (Rispens
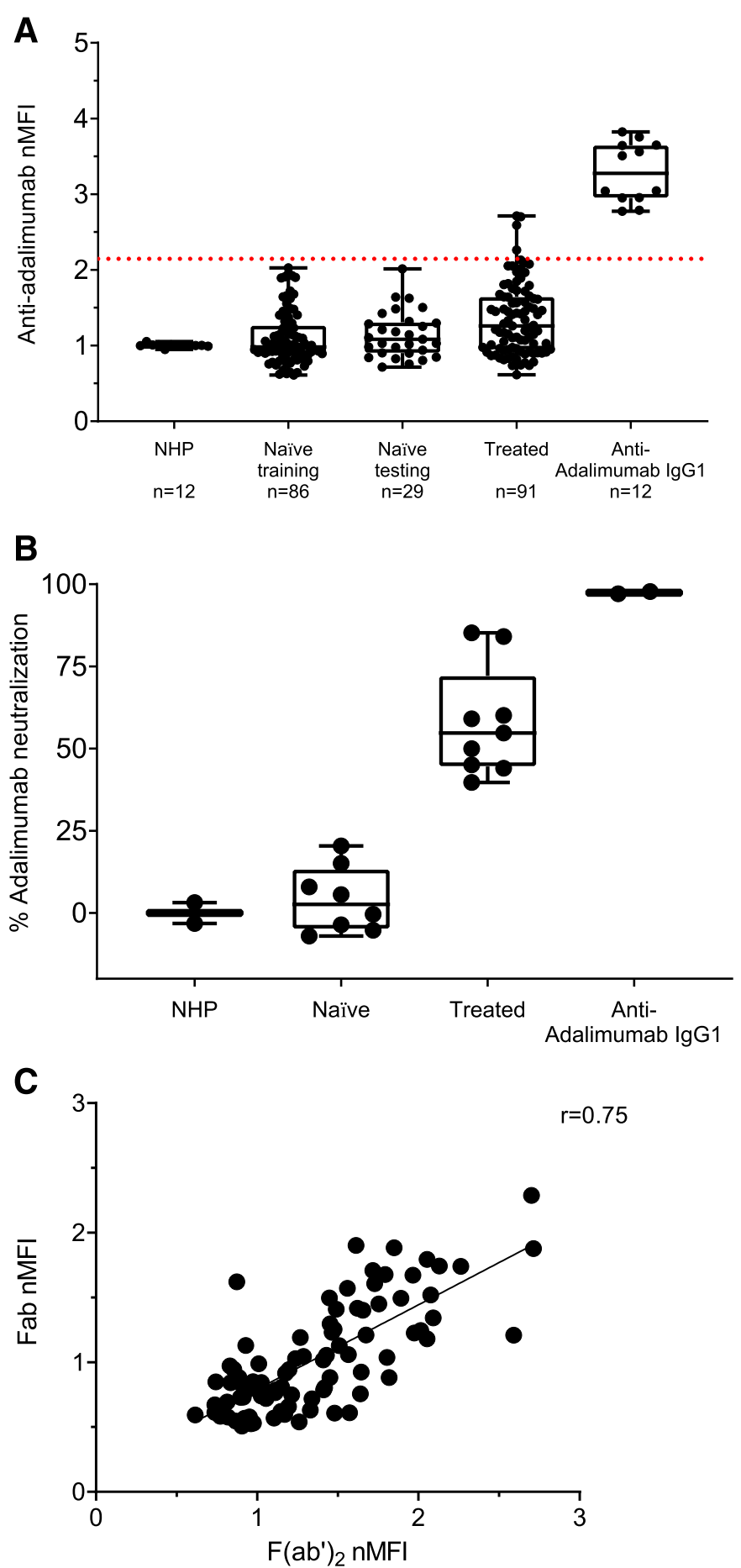

Fig. 4. RACER patients developed neutralizing anti-adalimumab antibodies during adalimumab treatment. (A) Using a subset of samples from patients naïve for adalimumab (naïve training) to estimate the antiadalimumab antibody threshold (horizontal line), we detected that four of ninety-one (4.4\%) patients were positive for anti-adalimumab antibodies. Neither the NHP nor naïve RACER samples testing set (naïve testing) were positive for anti-adalimumab antibodies. (B) The top $10 \%$ of samples with the highest anti-adalimumab MFI were evaluated for adalimumab neutralization and showed greater ex vivo adalimumab neutralization relative to samples from naïve patients and normal human plasma controls $(P<0.0001)$. (C) In patients treated with adalimumab, antiadalimumab antibodies detected using $\mathrm{Fab}$ and $\mathrm{F}\left(\mathrm{ab}^{\prime}\right)_{2}$ adalimumab fragments yield similar MFI signals. $n=90$ samples available for analysis. 
A

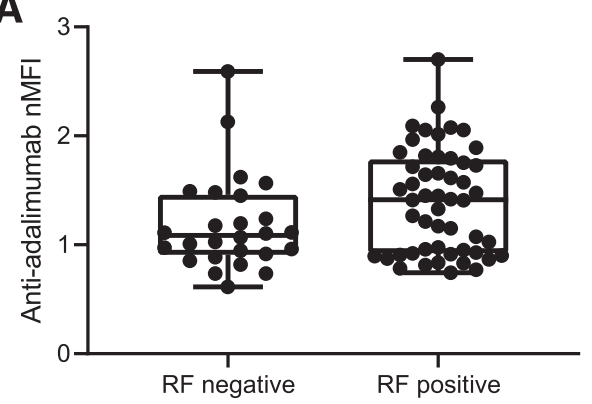

C

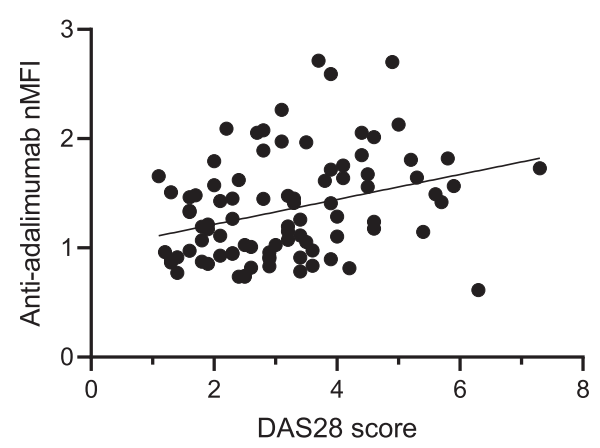

B
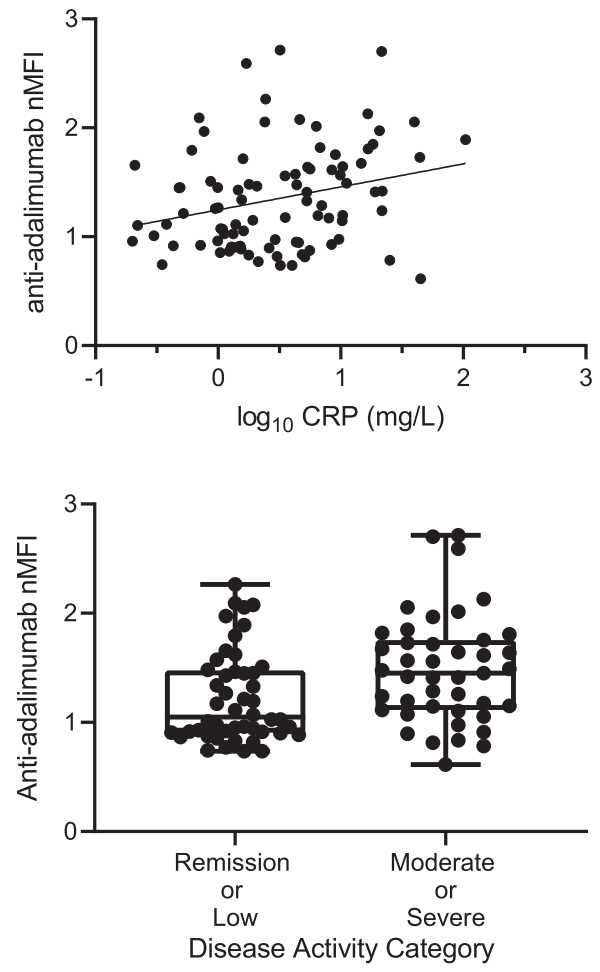

Fig. 5. Anti-adalimumab antibodies are associated with worse RA disease control. In patients treated with adalimumab, anti-adalimumab nMFI was positively associated with indicators of poorer disease control, including plasma (A) RF, (B) CRP, (C) DAS28 score, and (D) disease activity category. et al., 2012; van de Stadt et al., 2014). Interestingly, we found that patients with more anti-hinge antibodies were less likely to neutralize adalimumab (Fig. 6A) and that anti-hinge antibodies inversely correlate with anti-adalimumab antibodies (Fig. 6B). However, unlike anti-adalimumab antibodies, the presence of anti-hinge antibodies was not associated with markers of disease severity or rheumatoid factor positivity in our study, suggesting that the potential protective effect of anti-hinge antibodies against the development of antiadalimumab antibodies does not protect against other markers of RA autoimmunity. It has been suggested that anti-hinge antibodies may suppress B cells and antibody production (Terness and Opelz, 1998; Terness et al., 2002), but whether this extends to anti-drug antibodies is unknown. Others have found anti-hinge antibodies in the synovial fluid of patients with RA (Ryan et al., 2008), suggesting that they may exacerbate overall RA pathophysiology by restoring Fcmediated antibody effector function (Brezski et al., 2008; van de Stadt et al., 2014; Falkenburg et al., 2017; Trouw et al., 2017). Our results may, nevertheless, indicate that it may be possible to predict $\mathrm{TNF} \alpha$ inhibitor immunogenicity from preexisting anti-hinge antibody levels.

Although adalimumab is a fully human antibody, antiadalimumab antibodies still develop frequently, with a wide range in reported prevalence across studies from $6 \%$ to $87 \%$ of patients with RA (Emi Aikawa et al., 2010; Krieckaert et al., 2010). The methods used to detect anti-adalimumab antibodies in these studies varied (Gorovits et al., 2018), and as we have shown in this study, the presence of various unaccounted interference factors likely contributes to the reported variability. Additionally, the concomitant administration of methotrexate with adalimumab is associated with a decreased incidence of anti-adalimumab antibodies (Bartelds et al., 2007, 2010; Krieckaert et al., 2012), possibly because of the immunomodulatory effects of methotrexate via the adenosine pathway (Krieckaert et al., 2010; Jani et al., 2014). Theoretically, methotrexate could also reduce the levels of other interfering antibodies. Our findings that $4.4 \%$ of the RACER patients included in this study develop anti-adalimumab antibodies and that worse RA disease severity and autoimmunity are associated with anti-adalimumab antibodies are consistent with previous studies (Radstake et al., 2009; Bartelds et al., 2010, 2011) and possibly suggest that better disease control could also prevent the formation of anti-drug antibodies or that these factors prime patients to develop $\mathrm{TNF} \alpha$ inhibitor immune responses.

Patients with RA have an inherent autoimmune phenotype; therefore, the presence of these interfering antibodies and proclivity toward developing anti-drug antibodies are not unexpected (Volkov et al., 2020). However, our results underscore the need for appropriate testing methodologies in the target population, including the selection of appropriate disease-specific controls, as observed from the interindividual variability in anti-adalimumab nMFI signal (Fig. 4A). Clinically, it is imperative to identify the true antibody status of patients because therapeutic decisions are dependent on the source of therapeutic failure: whether the lack of efficacy is driven by neutralization from anti-drug antibodies or lack of pharmacodynamic response to anti-TNF $\alpha$ therapy. By providing timely and accurate drug concentration and neutralizing antibody information, pharmacotherapy for patients with RA can be optimized.

A limitation of our study is that adalimumab concentrations in patient samples were not measured, as a result of the lack of drug administration records in the home setting, although our simultaneous detection assay accurately detected spiked adalimumab. Likewise, measuring adalimumab neutralization for all the patients included in our study was not possible, because 


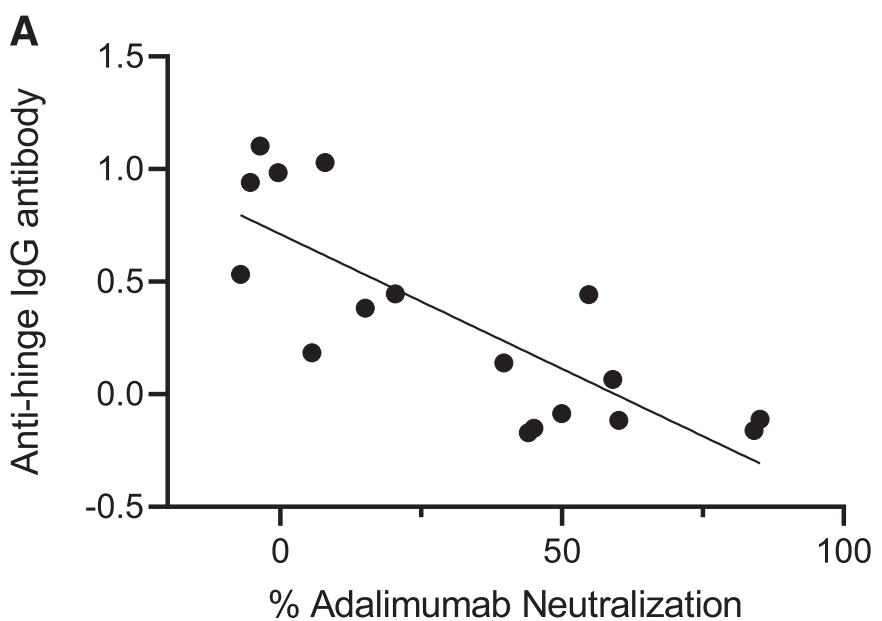

B

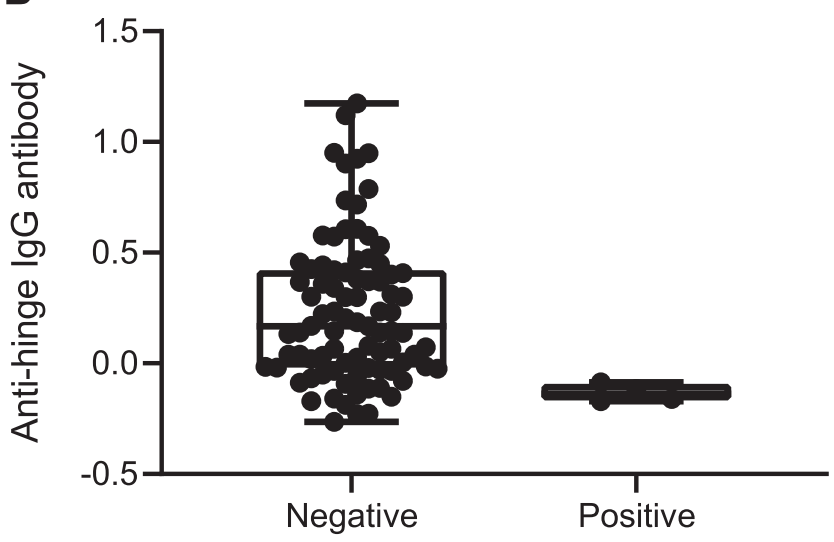

Anti-adalimumab antibody status

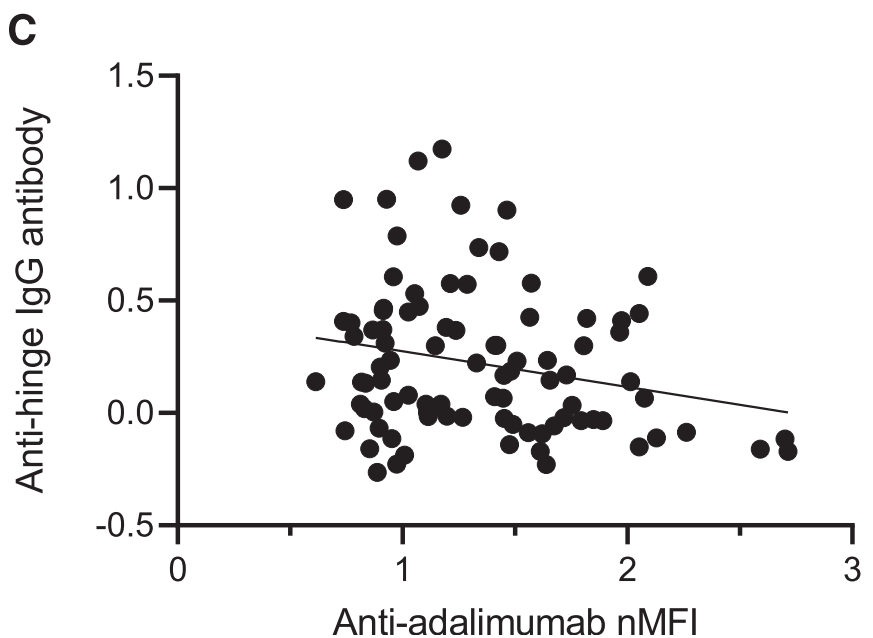

Fig. 6. Anti-hinge antibodies are inversely associated with antiadalimumab immunogenicity. Anti-hinge antibodies were negatively associated with (A) drug neutralization, (B) anti-adalimumab antibodies, and (C) anti-adalimumab antibody-positive status.

of sample limitations. Although we and others (Rispens et al., 2012 ) show that the autoantibodies against $\mathrm{F}\left(\mathrm{ab}^{\prime}\right)_{2}$ are primarily directed to the hinge region of immunoglobulins, we did not directly distinguish between interference resulting from antihinge or other possible regions that differ between the Fab and $\mathrm{F}\left(\mathrm{ab}^{\prime}\right)_{2}$ molecules. Additionally, the anti-adalimumab antibody positive threshold established can be further refined in a larger patient cohort to further capture interindividual variability. However, adding data from the adalimumab-naïve testing subset to the training subset to refine the threshold identified only one additional patient as positive for anti-adalimumab antibody, demonstrating the robustness of our results. Furthermore, we did not find an association between anti-adalimumab antibodies or anti-hinge interference and methotrexate use, but this was limited by data available and the high proportion of reported use in the RACER cohort. Our cohort of 206 patients with RA, of which 91 were treated with adalimumab, is still sizable and comparable to other trials (Bartelds et al., 2007; Chen et al., 2015), and the point estimate of the effect size of anti-adalimumab antibodies on disease severity (i.e., DAS28 scores) is similar relative to those reported previously (Garcês et al., 2013; Chen et al., 2015). Although our results suggest that increased adalimumab doses could overcome neutralization in settings of low anti-adalimumab antibody concentrations and has been successfully used previously (Bartelds et al., 2007), consideration needs to be given to potentially increased adverse effects. The threshold at which therapeutic substitution with alternative anti-TNF $\alpha$ therapy or other immunosuppressive agents should occur is unknown and requires further research. Finally, although age was statistically different between the adalimumab-treated versus naïve groups, it was associated with neither antiadalimumab nor anti-hinge signals, making it an unlikely clinical or biologic confounder.

Altogether, we identified factors in patients with RA that can interfere with conventional technologies used to monitor anti-TNF $\alpha$ therapy. We developed and validated a flow cytometry-based assay that overcomes these factors and can detect adalimumab and anti-adalimumab antibodies simultaneously in plasma from patients with RA. Results using this method may correlate better with patient response to anti$\mathrm{TNF} \alpha$ therapy and improve prediction of clinical efficacy. Finally, we showed that RA disease severity associates with anti-drug antibodies, whereas anti-hinge antibodies were inversely associated with drug neutralization and the development of anti-drug antibodies.

\section{Authorship Contributions}

Participated in research design: Hoshitsuki, Rathod, Moreland, Fernandez.

Conducted experiments: Rathod, Ramsey.

Performed data analysis: Hoshitsuki, Rathod, Zhu, Fernandez.

Wrote or contributed to the writing of the manuscript: Hoshitsuki, Rathod, Zhu, Moreland, Fernandez.

\section{References}

Aletaha D and Smolen JS (2018) Diagnosis and management of rheumatoid arthritis: a review. JAMA 320:1360-1372.

Bartelds GM, Krieckaert CL, Nurmohamed MT, van Schouwenburg PA, Lems WF, Twisk JW, Dijkmans BA, Aarden L, and Wolbink GJ (2011) Development of antidrug antibodies against adalimumab and association with disease activity and treatment failure during long-term follow-up. JAMA 305:1460-1468

Bartelds GM, Wijbrandts CA, Nurmohamed MT, Stapel S, Lems WF, Aarden L, Dijkmans BA, Tak PP, and Wolbink GJ (2007) Clinical response to adalimumab: relationship to anti-adalimumab antibodies and serum adalimumab concentrations in rheumatoid arthritis. Ann Rheum Dis 66:921-926.

Bartelds GM, Wijbrandts CA, Nurmohamed MT, Stapel S, Lems WF, Aarden L, Dijkmans BA, Tak PP, and Wolbink GJ (2010) Anti-infliximab and antiadalimumab antibodies in relation to response to adalimumab in infliximab switchers and anti-tumour necrosis factor naive patients: a cohort study. Ann Rheum Dis 69:817-821.

Bendtzen K (2015a) Immunogenicity of anti-TNF- $\alpha$ biotherapies: I. Individualized medicine based on immunopharmacological evidence. Front Immunol 6:152.

Bendtzen K (2015b) Immunogenicity of anti-TNF- $\alpha$ biotherapies: II. Clinical relevance of methods used for anti-drug antibody detection. Front Immunol 6:109. 
Brezski RJ, Luongo JL, Petrone D, Ryan MH, Zhong D, Tam SH, Schmidt AP, Kruszynski M, Whitaker BP, Knight DM, et al. (2008) Human anti-IgG1 hinge autoantibodies reconstitute the effector functions of proteolytically inactivated IgGs. J Immunol 181:3183-3192.

Chen DY, Chen YM, Tsai WC, Tseng JC, Chen YH, Hsieh CW, Hung WT, and Lan JL (2015) Significant associations of antidrug antibody levels with serum drug trough levels and therapeutic response of adalimumab and etanercept treatment in rheumatoid arthritis. Ann Rheum Dis 74:e16

Dörner T, Egerer K, Feist E, and Burmester GR (2004) Rheumatoid factor revisited. Curr Opin Rheumatol 16:246-253.

Emi Aikawa N, de Carvalho JF, Artur Almeida Silva C, and Bonfá E (2010) Immunogenicity of Anti-TNF-alpha agents in autoimmune diseases. Clin Rev Allergy Immunol 38:82-89.

Falkenburg WJ, van Schaardenburg D, Ooijevaar-de Heer P, Tsang-A-Sjoe MW, Bultink IE, Voskuyl AE, Bentlage AE, Vidarsson G, Wolbink G, and Rispens T (2017) Anti-hinge antibodies recognize IgG subclass- and protease-restricted neoepitopes. J Immunol 198:82-93.

Garcês S, Demengeot J, and Benito-Garcia E (2013) The immunogenicity of anti-TNF therapy in immune-mediated inflammatory diseases: a systematic review of the literature with a meta-analysis. Ann Rheum Dis 72:1947-1955.

Gorovits B, Baltrukonis DJ, Bhattacharya I, Birchler MA, Finco D, Sikkema D, Vincent MS, Lula S, Marshall L, and Hickling TP (2018) Immunoassay methods used in clinical studies for the detection of anti-drug antibodies to adalimumab and infliximab. Clin Exp Immunol 192:348-365.

Hart MH, de Vrieze H, Wouters D, Wolbink GJ, Killestein J, de Groot ER, Aarden LA, and Rispens T (2011) Differential effect of drug interference in immunogenicity assays. J Immunol Methods 372:196-203.

Jani M, Barton A, Warren RB, Griffiths CE, and Chinoy H (2014) The role of DMARDs in reducing the immunogenicity of TNF inhibitors in chronic in flammatory diseases. Rheumatology (Oxford) 53:213-222.

Jani M, Chinoy H, Warren RB, Griffiths CEM, Plant D, Fu B, Morgan AW, Wilson AG, Isaacs JD, Hyrich K, et al.; Biologics in Rheumatoid Arthritis Genetics and Genomics Study Syndicate Collaborators (2015) Clinical utility of random antitumor necrosis factor drug-level testing and measurement of antidrug antibodies on the long-term treatment response in rheumatoid arthritis [published correction appears in Arthritis Rheumatol (2015) 67:3096]. Arthritis Rheumatol 67: $2011-2019$

Keystone EC, Kavanaugh AF, Sharp JT, Tannenbaum H, Hua Y, Teoh LS, Fischkoff SA, and Chartash EK (2004) Radiographic, clinical, and functional outcomes of treatment with adalimumab (a human anti-tumor necrosis factor monoclonal antibody) in patients with active rheumatoid arthritis receiving concomitant methotrexate therapy: a randomized, placebo-controlled, 52-week trial. Arthritis Rheum 50:1400-1411.

Krieckaert CL, Bartelds GM, Lems WF, and Wolbink GJ (2010) The effect of immunomodulators on the immunogenicity of TNF-blocking therapeutic monoclonal antibodies: a review. Arthritis Res Ther 12:217.

Krieckaert CL, Nurmohamed MT, and Wolbink GJ (2012) Methotrexate reduces immunogenicity in adalimumab treated rheumatoid arthritis patients in a dose dependent manner. Ann Rheum Dis 71:1914-1915.

Mian A, Ibrahim F, and Scott DL (2019) A systematic review of guidelines for managing rheumatoid arthritis. BMC Rheumatol 3:42.

Navarro-Sarabia F, Ariza-Ariza R, Hernandez-Cruz B, and Villanueva I (2005) Adalimumab for treating rheumatoid arthritis. Cochrane Database Syst Rev: CD005113.

Ogrič M, Terčelj M, Praprotnik S, Tomšič M, Božič B, Sodin-Semrl S, and Čučnik S (2017) Detection of adalimumab and anti-adalimumab antibodies in patients with rheumatoid arthritis: a comprehensive overview of methodology pitfalls and benefits. Immunol Res 65:172-185.

Radstake TR, Svenson M, Eijsbouts AM, van den Hoogen FH, Enevold C, van Riel PL, and Bendtzen K (2009) Formation of antibodies against infliximab and adalimumab strongly correlates with functional drug levels and clinical responses in rheumatoid arthritis. Ann Rheum Dis 68:1739-1745.
Rispens T, de Vrieze H, de Groot E, Wouters D, Stapel S, Wolbink GJ, and Aarden LA (2012) Antibodies to constant domains of therapeutic monoclonal antibodies: antihinge antibodies in immunogenicity testing. J Immunol Methods 375:93-99.

Rispens T, Hart MH, Ooijevaar-de Heer P, van Leeuwen A, Vennegoor A, Killestein J, Wolbink GJ, and van der Kleij D (2013) Drug interference in immunogenicity assays depends on valency. $J$ Pharm Biomed Anal 85:179-185.

Ryan MH, Petrone D, Nemeth JF, Barnathan E, Björck L, and Jordan RE (2008) Proteolysis of purified IgGs by human and bacterial enzymes in vitro and the detection of specific proteolytic fragments of endogenous IgG in rheumatoid synovial fluid. Mol Immunol 45:1837-1846.

Singh JA, Saag KG, Bridges SL Jr, Akl EA, Bannuru RR, Sullivan MC, Vaysbrot E, McNaughton C, Osani M, Shmerling RH, et al. American College of Rheumatology (2016) 2015 American College of Rheumatology guideline for the treatment of rheumatoid arthritis. Arthritis Care Res (Hoboken) 68:1-25.

Smolen JS, Landewé R, Bijlsma J, Burmester G, Chatzidionysiou K, Dougados M, Nam J, Ramiro S, Voshaar M, van Vollenhoven R, et al. (2017) EULAR recommendations for the management of rheumatoid arthritis with synthetic and biological disease-modifying antirheumatic drugs: 2016 update. Ann Rheum Dis 76: 960-977.

Strand V, Gonçalves J, Hickling TP, Jones HE, Marshall L, and Isaacs JD (2020) Immunogenicity of biosimilars for rheumatic diseases, plaque psoriasis, and inflammatory bowel disease: a review from clinical trials and regulatory documents. BioDrugs 34:27-37.

Tatarewicz S, Miller JM, Swanson SJ, and Moxness MS (2010) Rheumatoid factor interference in immunogenicity assays for human monoclonal antibody therapeutics. J Immunol Methods 357:10-16.

Terness P and Opelz G (1998) Natural anti-immunoglobulin autoantibodies: irrelevant by-products or immunoregulatory molecules? Int Arch Allergy Immunol 115 270-277.

Terness PI, Navolan D, Dufter C, Welschof M, and Opelz G (2002) Immunosuppressive anti-immunoglobulin autoantibodies: specificity, gene structure and function in health and disease. Cell Mol Biol 48:271-278.

Trouw LA, Rispens T, and Toes REM (2017) Beyond citrullination: other posttranslational protein modifications in rheumatoid arthritis. Nat Rev Rheumatol 13: 331-339.

van de Stadt LA, de Vrieze H, Derksen NI, Brouwer M, Wouters D, van Schaardenburg D, Wolbink G, and Rispens T (2014) Antibodies to IgG4 hinge can be found in rheumatoid arthritis patients during all stages of disease and may exacerbate chronic antibody-mediated inflammation. Arthritis Rheumatol 66 1133-1140.

van Schouwenburg PA, Krieckaert CL, Nurmohamed M, Hart M, Rispens T, Aarden L, Wouters D, and Wolbink GJ (2012) IgG4 production against adalimumab during long term treatment of RA patients. J Clin Immunol 32:1000-1006.

van Schouwenburg PA, Rispens T, and Wolbink GJ (2013) Immunogenicity of antiTNF biologic therapies for rheumatoid arthritis. Nat Rev Rheumatol 9:164-172.

Volkov M, van Schie KA, and van der Woude D (2020) Autoantibodies and B Cells: the $\mathrm{ABC}$ of rheumatoid arthritis pathophysiology. Immunol Rev 294:148-163.

Weinblatt ME, Keystone EC, Furst DE, Moreland LW, Weisman MH, Birbara CA Teoh LA, Fischkoff SA, and Chartash EK (2003) Adalimumab, a fully human antitumor necrosis factor alpha monoclonal antibody, for the treatment of rheumatoid arthritis in patients taking concomitant methotrexate: the ARMADA trial. Arthritis Rheum 48:35-45.

Williams PM, Lively TG, Jessup JM, and Conley BA (2012) Bridging the gap: moving predictive and prognostic assays from research to clinical use. Clin Cancer Res 18: 1531-1539.

Address correspondence to: Dr. Christian A. Fernandez, Center for Pharmacogenetics and Department of Pharmaceutical Sciences, School of Pharmacy, University of Pittsburgh, 335 Sutherland Drive, Pittsburgh, PA 15261. E-mail: chf63@pitt.edu 